\title{
Community structure and vertical distribution of cyclopoid and poecilostomatoid copepods in the Red Sea. III. Re-evaluation for separating a new species of Oncaea
}

\author{
Ruth Böttger-Schnack* \\ Institut für Hydrobiologie und Fischereiwissenschaft, Zeiseweg 9, W-2000 Hamburg 50, Germany
}

\begin{abstract}
Fine mesh net samples from the upper mesopelagic zone $(100$ to $450 \mathrm{~m})$ of the central and northern Red Sea during autumn and winter 1980-81 were re-examined to separate the abundance and vertical distribution of 2 very similar small Oncaea species, O. tregoubovi and Oncaea sp. $\mathrm{K}$, which previously had been considered as a single species. O. tregoubovi is more abundant and lives at deeper layers than Oncaea sp. K. The new results alter the ranks of important cyclopoid and poecilostomatoid species in both subzones of the upper mesopelagic zone, although the dominance of O. tregoubovi in the lower part, at 250 to $450 \mathrm{~m}$, still remains very high.
\end{abstract}

In a detailed study on the abundances and vertical distribution patterns of small pelagic cyclopoid and poecilostomatoid copepods from the central and northern Red Sea during autumn and winter 1980-81 (Böttger-Schnack 1988, 1990a, b), Oncaea tregoubovi Shmeleva was reported to be one of the most numerous species in the upper mesopelagic zone, dominating especially in the 250 to $450 \mathrm{~m}$ depth layer. In the course of a recent analysis of microcopepods sampled in the same area during summer 1987 (BöttgerSchnack unpubl.) it was noticed that the taxon previously identified as $O$. tregoubovi also included a very similar species, which is still unidentified and referred to as Oncaea sp. K hereafter (see Böttger-Schnack 1988).

Oncaea sp. $\mathrm{K}$ is similar to O. ivlevi Shmeleva in the shape of the caudal rami and genital segment, but lacks the conspicuous stout spine on the external

- Present address: Institut für Meereskunde an der Universität Kiel, Düsternbrooker Weg 20, W-2300 Kiel 1, Germany posterior margin of caudal rami. It also resembles O. prendeli Shmeleva in certain characters, but differences in body proportions and the length ratio of the genital segment to the rest of the urosome segments separate the 2 species. The taxonomic description of these small Oncaea species is rather poor. $O$. ivlevi and O. prendeli were first described by Shmeleva (1966, 1969), O. tregoubovi was described by Shmeleva $(1968,1969)$. A redescription of both sexes of $O$. ivlevi and of female $O$. tregoubovi was given by Malt (1982). A more detailed description of this taxon from the Red Sea is needed.

The present study re-examines the autumn-winter plankton material obtained with a fine mesh net from the Red Sea to separate Oncaea tregoubovi and Oncaea sp. K quantitatively. The new data complement and revise the earlier results on community structure and vertical distribution of cyclopoid and poecilostomatoid copepods given by Böttger-Schnack (1988, 1990a, b).

Methods. The quantitative re-analysis of the 2 species was conducted on subsamples from 11 vertical profiles which had been taken with a $0.1 \mathrm{~mm}$ mesh multiple opening-closing net at $50 \mathrm{~m}$ intervals, between depths of 100 and $450 \mathrm{~m}$. Samples from the epipelagic zone $(0$ to $100 \mathrm{~m})$ were not re-evaluated quantitatively, as they were known to contain only very small numbers of the species $(<5 \%$ of the total standing stock of both species combined). Three vertical daytime series were each analysed from the central Red Sea (above Atlantis II Deep) during autumn (October-November 1980) and winter (February 1981) and from the northern Red Sea (above Kebrit Deep) 

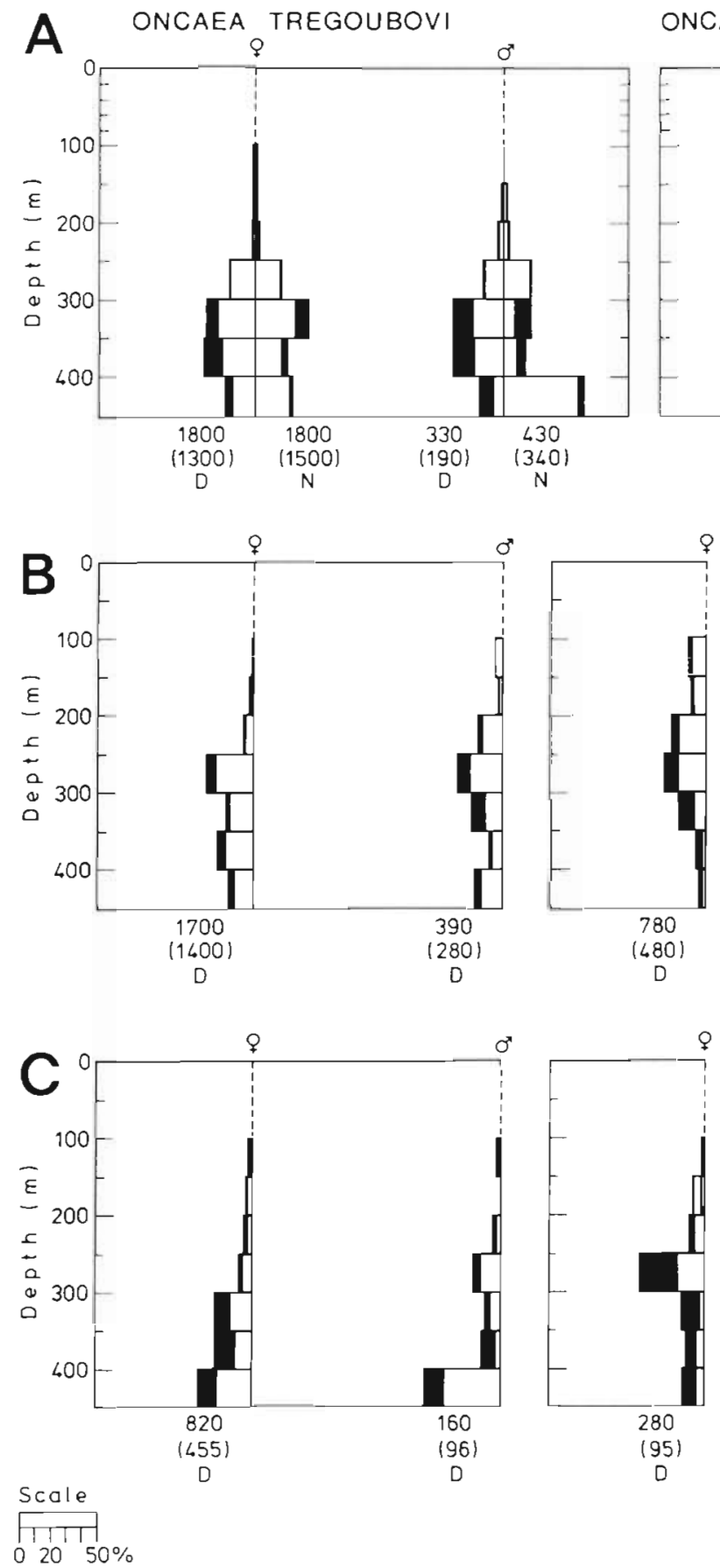

$2050 \%$

during autumn 1980. Two nighttime series from the central Red Sea during autumn were also re-evaluated in order to investigate possible diurnal vertical migration of the species. For details of the sampling methods, subsampling techniques, criteria for the determination of carcasses, and environmental data during the sampling period see Böttger-Schnack (1990a, b).

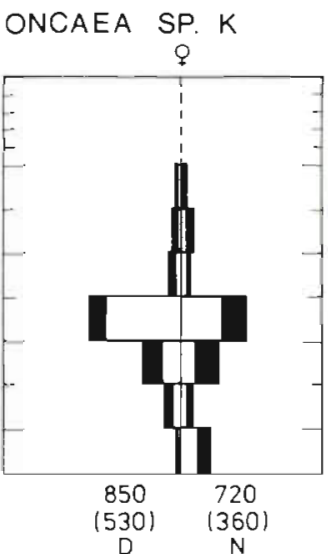

Fig. 1 Oncaea tregoubovi (left panels), Oncaea sp. K (right panels). Corrected vertical distributions during day (D) and night $(N)$ in the central Red Sea during (A) autumn and (B) winter, and (C) in the northern Red Sea during autumn. Percentage values are given per $50 \mathrm{~m}$ depth interval. Mean total standing stocks of dead and living individuals beneath $0.25 \mathrm{~m}^{2}$ in the 100 to $450 \mathrm{~m}$ layer given below each profile were calculated using new data from second analysis (see text); values in parentheses refer to the total number of living individuals. Unfilled bar: living ind.; solid bar: dead ind

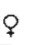

Oncaea sp. K was distinguished from $O$. tregoubovi by the different body forms, the ornamentation of the maxilliped, and the presence of a long 'saw-like' median caudal seta in both sexes of $O$. tregoubovi, which was not noticed in the descriptions of Shmeleva (1968, 1969) and Malt (1982). Adult copepods were separated by species and sex. Carcasses were counted separately. Total number of individuals observed during the second analysis was about 5 to $10 \%$ lower than during the first analysis. Besides some loss of these tiny organisms during handling and/or some counting error, this may have been mainly due to fragmentation of fragile carcasses after the first counting and a different separation of 'dead' and 'living' individuals between the 2 studies.

The new data from this second analysis were used to calculate the percentage depth distribution of both species within the 100 to $450 \mathrm{~m}$ depth layer (Fig. 1). Weighted mean values for standing stock of dead and living individuals given below each profile in Fig. 1 are also restricted to this depth range. Values were derived from pooled day and night samples, respectively. Corresponding values from individual vertical series of the complete analysis differed by less than $5 \%$.

For incorporation into the preceding complete analysis of the cyclopoid and poecilostomatoid community, revised absolute and relative abundance values were obtained for both species by splitting the originally combined values (Böttger-Schnack 1988, Table 2, and 1990b, Tables 1, 4 \& 5) according to the abundance ratios derived from the present analysis.

Results and discussion. Independent of seasonal and regional differences, the following generalizations can be made with regard to the population characteristics of the 2 species in the Red Sea. Compared to Oncaea tregoubovi the population of Oncaea sp. K lives at shallower depths (Fig. 1), occurs in lower total abundance (Table 1), includes a lower proportion of males (Table 2) and has a higher proportion of carcasses (Fig. 1), 
Table 1. Oncaea tregoubovi, Oncaea sp. K. Corrected daytime standing stocks in the upper $450 \mathrm{~m}$ of the central and northern Red Sea during autumn and winter 1980-81 Abundance values were calculated by splitting the abundance data of the first analysis (Böttger-Schnack 1988, Table 2, and 1990b. Tables 1 \& 5) according to the abundance ratio obtained during the re-examination (see text). $\bar{x}$ : Mean abundance beneath $0.25 \mathrm{~m}^{2}$; $\mathrm{R}$ : range; \%: mean percentage of each species of total number. Sexes are (F) females, $(M)$ males

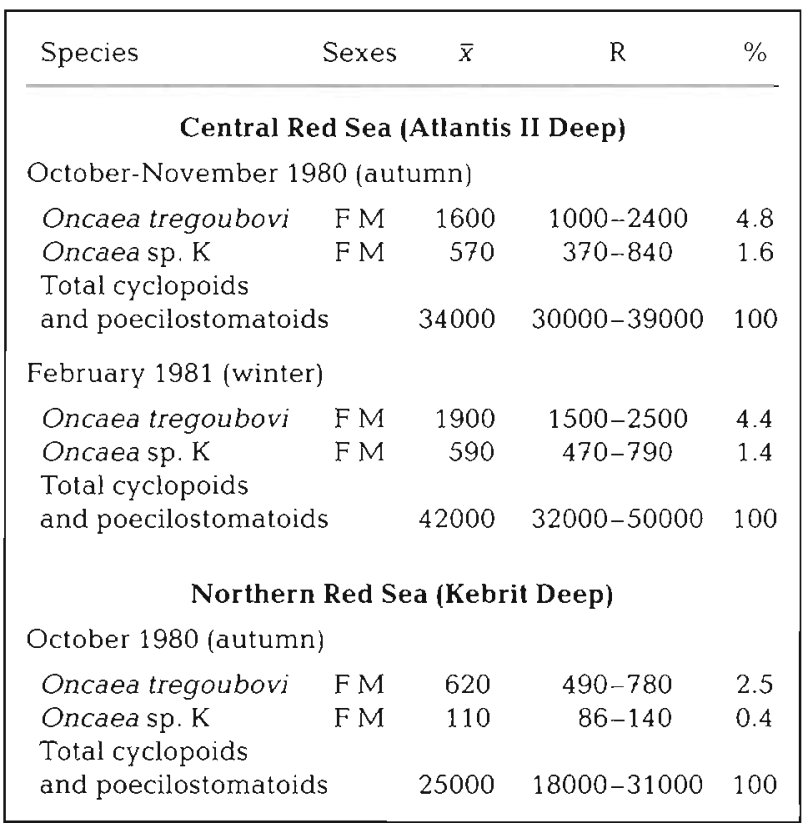

Table 2. Oncaea tregoubovi, Oncaea sp. K. Percentage of males in adult populations in the Red Sea. Arithmetic mean $(\bar{x})$ and range (R) were derived from the pooled data of 3 vertical series in the 100 to $450 \mathrm{~m}$ depth layer taken during daytime

\begin{tabular}{|c|c|c|}
\hline Species & $\bar{x}$ & $\mathrm{R}$ \\
\hline \multicolumn{3}{|c|}{ Central Red Sea (Atlantis II Deep) } \\
\hline \multicolumn{3}{|c|}{ October-November 1980 (autumn) } \\
\hline $\begin{array}{l}\text { Oncaea tregoubovi } \\
\text { Oncaea sp. K }\end{array}$ & $\begin{array}{r}12.5 \\
2.4\end{array}$ & $\begin{array}{r}12-14 \\
0-4.8\end{array}$ \\
\hline $\begin{array}{l}\text { Oncaea tregoubovi } \\
\text { Oncaea sp. K }\end{array}$ & $\begin{array}{l}17 \\
3.9\end{array}$ & $\begin{array}{l}12-20 \\
1.6-5.7\end{array}$ \\
\hline \multicolumn{3}{|c|}{ Northern Red Sea (Kebrit Deep) } \\
\hline \multicolumn{3}{|l|}{ October 1980} \\
\hline $\begin{array}{l}\text { Oncaea tregoubovi } \\
\text { Oncaea sp. } \mathrm{K}\end{array}$ & $\begin{array}{l}17 \\
2.8\end{array}$ & $\begin{array}{r}11-25 \\
0-5.0\end{array}$ \\
\hline
\end{tabular}

In the central Red Sea during autumn, female Oncaea tregoubovi were more or less evenly distributed between 250 and $450 \mathrm{~m}$, with no obvious diurnal vertical movement (Fig. 1A). Males had a similar depth distribution to females during the day but showed a conspicuous accumulation in the 400 to $450 \mathrm{~m}$ depth layer at night (Fig. 1A). Female Oncaea sp. $K$ occurred mainly at 250 to $300 \mathrm{~m}$ with no diurnal variation (Fig. 1A). Male Oncaea sp. K were caught irregularly and mostly between 100 and $300 \mathrm{~m}$, their numbers were too low to allow for a reliable calculation of their percentage depth distribution.

In a recent analysis of sampling series taken down to 1050 m during summer 1987, it was found that Oncaea tregoubovi occurred in high abundances also in the lower mesopelagic zone at 450 to $600 \mathrm{~m}$ (BöttgerSchnack unpubl.). Thus, the interpretation of the present data on vertical migration for this species has to be done with care, since only samples above this depth were considered.

Comparing the results from autumn and winter in the central Red Sea, differences in the abundance (Table 1), the sex ratio (Table 2) and vertical distribution (Fig. 1B) of both species were only minor.

Comparing the results from the central and northern Red Sea during autumn, more pronounced differences were found for the 2 species: the standing stocks of living individuals were lower (Table 1) and the percentages of carcasses were higher in the north (Fig. 1A, C). Oncaea sp. K seemed to find less favourable conditions in the northern area than $O$. tregoubovi, judged by the somewhat stronger decrease in number and the stronger increase in the proportion of carcasses. The vertical distribution of both sexes of $O$. tregoubovi showed a downward shift by about 50 to $100 \mathrm{~m}$ to the north (Fig. 1C). A similar observation had previously been made for several other oncaeid species (Böttger-Schnack 1990b). It corresponds with differences in the depth of the oxygen-minimum zone, which was situated ca $100 \mathrm{~m}$ deeper in the northern region than in the central part. For female $O$. tregoubovi, however, the regional change in vertical distribution had not been previously noted, due to the combination with female Oncaea sp. K.

Table 3 [from Table 4 of Böttger-Schnack (1990b)] summarizes the absolute and relative abundances of dominant cyclopoid and poecilostomatoid species, i.e. those contributing more than $1 \%$ to the total number in a respective layer, for the 2 different vertical zones investigated in the present study. Due to the separation of Oncaea sp. K, previously combined with $O$. tregoubovi, there are some changes in ranking the species in both subzones of the upper mesopelagic zone. O. tregoubovi, however, still remains one of the most numerous species in the lower part of the upper mesopelagic zone, at 250 to $450 \mathrm{~m}$ (Table 3 ). 
Table 3. Corrected daytime standing stock $\left(n=\right.$ no. ind. beneath $\left.0.25 \mathrm{~m}^{2}\right)$ and percentages of total numbers in a layer $(\%)$ of dominant cyclopoid and poecilostomatoid species in the upper mesopelagic zone in the central (Atlantis II Deep) and northern (Kebrit Deep) Red Sea during winter and autumn 1980-81. Only species contributing more than $1 \%$ to the total cyclopoids and poecilostomatoids in a given layer are considered. Species listed in order of decreasing n. Corrected values for Oncaea tregoubovi and Oncaea sp. K are given in bold (for calculation see 'Methods')

\begin{tabular}{|c|c|c|c|c|c|c|c|c|}
\hline \multicolumn{3}{|c|}{ Central Red Sea, winter 1981} & \multicolumn{3}{|c|}{ Central Red Sea, autumn 1980} & \multicolumn{3}{|c|}{ Northern Red Sea, autumn 1980} \\
\hline Species $^{\mathrm{d}}$ & $\mathrm{n}$ & $\%$ & Species $^{b}$ & n & $\%$ & Species $^{c}$ & $\mathrm{n}$ & $\%$ \\
\hline \multicolumn{9}{|c|}{ Upper mesopelagic, $\mathrm{O}_{2}$-gradient $(100-250 \mathrm{~m})$} \\
\hline Paroithona sp. & 1800 & 20 & Paroithona sp. & 850 & 16 & Paroithona sp. & 920 & 22 \\
\hline Oncaea zernovi & 1150 & 13 & Oncaea zernovi & 750 & 14 & Oncaea zernovi & 480 & 12 \\
\hline Oncaea dentipes & 370 & 4.2 & Oncaea dentipes & 270 & 5.3 & Oncaea dentipes & 360 & 8.9 \\
\hline Oncaea ivlevi & 280 & 3.2 & Oncaea ovalis & 250 & 4.9 & Oncaea ivlevi & 120 & 2.9 \\
\hline Oncaea sp. K & 255 & 2.9 & Oncaea ivlevi & 240 & 4.7 & Oncaea minuta & 100 & 2.5 \\
\hline Oncaea tregoubovi & 225 & 2.6 & Oncaea media f. minor & 220 & 4.3 & Oncaea ovalis & 83 & 2.0 \\
\hline Oncaea minuta & 175 & 2.0 & Oithona simplex & 155 & 3.0 & Oithona simplex & 81 & 2.0 \\
\hline Oncaea simplex & 130 & 1.5 & Oncaea sp. K & 53 & 1.0 & Oncaea media f. minor & 46 & 1.6 \\
\hline Oncaea media f. minor & 120 & 1.4 & & & & Oncaea tregoubovi & 45 & 1.5 \\
\hline Oncaea ovalis & 120 & 1.3 & & & & & & \\
\hline \multicolumn{9}{|c|}{ Upper mesopelagic, $\mathrm{O}_{2}$-minimum $(250-450 \mathrm{~m})$} \\
\hline Oncaea tregoubovi & 1600 & 29 & Oncaea tregoubovi & 1500 & 27 & Oncaea ovalis & 910 & 30 \\
\hline Oncaea ovalis & 1000 & 18 & Oncaea ovalis & 1100 & 19 & Oncaea tregoubovi & 550 & 18 \\
\hline Oncaea zernovi & 680 & 13 & Oncaea sp. K & 500 & 9.1 & Oncaea zernovi & 390 & 13 \\
\hline Oncaea media f minor & 410 & 7.6 & Oncaea zemovi & 320 & 5.6 & Oncaea media f. minor & 175 & 5.8 \\
\hline Oncaea sp. K & 265 & 4.8 & Oncaea media f minor & 250 & 4.4 & Oncaea minuta & 120 & 4.1 \\
\hline Paroithona sp. & 71 & 1.3 & Paroithona sp. & 160 & 2.8 & Oncaea sp. K & 85 & 2.8 \\
\hline \multirow[t]{4}{*}{ Oncaea ivlevi } & 56 & 1.0 & Oncaea ivlevi & 160 & 2.8 & Paroithona sp. & 73 & 2.4 \\
\hline & & & Oncaea hawii ${ }^{\mathrm{d}}$ & 120 & 2.2 & Oncaea ivlevi & 54 & 1.8 \\
\hline & & & Lubbockia squillimana & 82 & 1.4 & Lubbockia squillimana & 52 & 1.7 \\
\hline & & & Oncaea minuta & 82 & 1.4 & Oncaea hawii $k^{\circ}$ & 37 & 1.2 \\
\hline \multicolumn{9}{|c|}{$\begin{array}{l}\text { a Sexes/stages given in Table } 1 \text { of Böttger-Schnack (1990b) } \\
\text { bSexes/stages given in Table } 1 \text { of Böttger-Schnack (1990a) } \\
\text { ¿Sexes/stages given in Table } 5 \text { of Böttger-Schnack (1990b) } \\
\text { d Oncaea sp. E/F in Böttger-Schnack (1990a b) }\end{array}$} \\
\hline
\end{tabular}

Acknowledgements. I thank Prof. D. Schnack for many constructive comments and Dr $\mathrm{H}$. Weikert for support and help. I am indebted to Dr G. A. Boxshall for valuable taxonomic advice. He and Dr R. J. Conover commented on the manuscript. This study was supported by Deutsche Forschungsgemeinschaft grant We 695/12 to $\mathrm{H}$. Weikert.

\section{LITERATURE CITED}

Böttger-Schnack, R. (1988). Observations on the taxonomic composition and vertical distribution of cyclopoid copepods in the central Red Sea. In: Boxshall, G. A., Schminke, H. K. (eds.) Biology of copepods. Proc. Third Int. Conf. on Copepoda. Hydrobiologia 167/168. KIuwer Academic Press, Dordrecht, p. 311-318

Böttger-Schnack, R. (1990a). Community structure and vertical

This note was submitted to the editor distribution of cyclopoid copepods in the Red Sea. I. Central Red Sea, autumn 1980. Mar. Biol. 106: 473-485 Böttger-Schnack, R.(1990b). Community structure and vertical distribution of cyclopoid copepods in the Red Sea. II. Aspects of seasonal and regional differences. Mar. Biol. 106: $487-501$

Malt, S. J. (1982). New and little known species of Oncaeidae (Cyclopoida) from the Northeastern Atlantic. Bull. Br. Mus. nat. Hist. (Zool.) 42: 185-205

Shmeleva, A. A. (1966). New species of the genus Oncaea (Copepoda, Cyclopoida) from the Adriatic Sea. Zool. Zh. 45: $932-935$ (in Russian)

Shmeleva, A. A. (1968). New species of planktonic Copepoda: Cyclopoida from the Adriatic Sea. Zool. Zh. 47: 1784-1793 (in Russian)

Shmeleva, A. A. (1969). Espèces nouvelles du genre Oncaea (Copepoda, Cyclopoida) de la mer Adriatique. Bull. Inst. Oceanogr. 68 (1393): 1-28

Manuscript first received: September 9, 1991 Revised version accepted: January 28, 1992 